\title{
In Memoriam: Dr. Julián Santiago-Prowald, Senior Advisor for the Structures, Mechanisms and Materials Division of ESA (1969-2018)
}

\author{
Santiago Pindado ${ }^{1}$ (D)
}

Received: 17 December 2018 / Accepted: 21 December 2018

(c) CEAS 2019

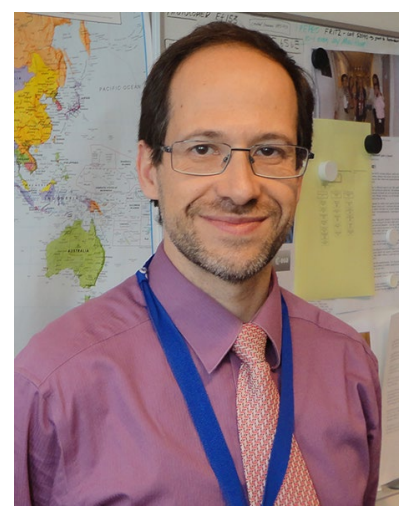

Dr. Julián Santiago-Prowald passed away on December 4, 2018, in Wassenaar, Netherlands, after a long illness.

Julián and I met while studying Aerospace Engineering at Universidad Politécnica de Madrid. We soon discovered that in addition to our interest in subjects such as Fluid Mechanics and Aerodynamics, we shared a passion for music. This led to an enduring friendship that never wavered until his death.

Julián's academic achievements were notable during his university years. After overcoming the challenges of the most demanding degree program in Spain at the time, he was invited to join the research team led by Professor José Meseguer. This group enjoyed international prestige in spacecraft thermal control and microgravity. During this period, Julián worked on a variety of scientific and technical projects, including the development of Spain's first university-built satellite, UPMSAT-1, launched in 1995.

Santiago Pindado

santiago.pindado@upm.es

1 Instituto Universitario de Microgravedad "Ignacio Da Riva" (IDR/UPM), Universidad Politécnica de Madrid, ETSI Aeronáutica y del Espacio, Pza. del Cardenal Cisneros 3, 28040 Madrid, Spain

As a result of this project, after starting work at CASA Espacio, Julián did his doctoral thesis on accelerometer calibration for space applications. This thesis, defended in the year 2000, earned him a unanimous Summa Cum Laude. Since its open-access publication, Julián's thesis has been downloaded 4524 times (958 in 2018), from more than 80 different countries. During that time, Julián participated as an engineer in a number of missions, including Artemis, EURASIASat, Mars Express, Rosetta, and Ariane.

In 2002, Julián began working for the European Space Agency (ESA), where he eventually became Head of the Structures Section, within the Structures, Mechanisms and Materials Division. Julián contributed to the success of numerous ESA missions, including Sentinel-1, Herschel, Planck, and Bepi-Colombo.

In addition to his extraordinary abilities as an engineer, Julián was a brilliant scientist who produced five patents and numerous publications. Furthermore, his essential contribution in preparing the Special Issue on Large Deployable Antennas for the CEAS Space Journal's December issue in 2013, and in writing a corresponding review paper together with Professor Baier, should be mentioned.

In his academic endeavors as a professor at Universidad Politécnica de Madrid, he directed a number of master's and doctoral theses. Julián never lost touch with his Alma Mater. In his last decade, he often served on doctoral thesis committees in the field of aerospace engineering, and as a guest lecturer for the Master's Degree in Space Systems program (MUSE).

However, Julián Santiago-Prowald's exceptional career was only one facet of his life. As husband to Tania Tate and father of two sons, Adrián and David, Julián was devoted to his family. This was obvious to all of his friends, whom he always welcomed lovingly into his home. Julián inherited two coexisting cultural traditions from his parents: those of Spain and Germany. From the former, I would highlight the extraordinary personal responsibility he put into everything 
he undertook. From the latter, I would emphasize just how much he demanded of himself, in his work as well as his personal pursuits. An excellent case in point is his impressive talent as an amateur violinist. I was fortunate enough to listen to J.S. Bach's Chaconne for Violin with Julián and his wife, Tania, during the last days of his life. In spite of his condition, he clung to every note of that 14-min miracle. The music of Bach contained the very essence of Julián as a person.
Those who knew him, loved him. And his memory will be with us always.

Sit tibi terra levis, Julián.

Translation from Spanish: Tania Tate.

Information relating to ESA and CASA Espacio provided by Gonçalo Rodrigues, Torben Henriksen and Heiko Ritter. 